\title{
PERHITUNGAN TEMPERATUR RESERVOIR PANAS BUMI DERAH BANTARKAWUNG MENGGUNAKAN METODE GEOTERMOMETER Na-K DAN ENTALPI-SILIKA
}

\author{
Sachrul Iswahyudi, Laskarul Wildan Attabik, Rachmad Setijadi, Sukmaji Anom Raharjo \\ Departemen Teknik Geologi, Universitas Jenderal Soedirman \\ e-mail : sachrul.iswahyudi@unsoed.ac.id
}

\begin{abstract}
Abstrak. Manifestasi panas bumi yang muncul di daerah Bantarkawung dan sekitarnya sebagai refleksi sistem panas bumi adalah berupa mata air panas. Beberapa mata air panas yang muncul yaitu Mata Air Panas Cipanas dan Mata Air Panas Cilakar. Keberadaan mata air panas juga diikuti dengan keberadaan mata air dingin, beberapa diantaranya yaitu Mata Air Meteorik Warudoyong dan Mata Air Meteorik Cilimus sebagai data penunjang penelitian. Analisis yang digunakan pada penelitian adalah metode geokimia yang diolah berdasarkan data penelitian terdahulu untuk mengetahui tipe air panas bumi, geoindikator dan kesetimbangan fluida. Penentuan temperatur panas bumi daerah penelitian menggunakan dua metode yaitu metode geotermometer $\mathrm{Na}-\mathrm{K}$ yang berdasar pada kandungan natrium dan kalium mata air panas dan metode diagram silika-entalpi yang berdasar kandungan silika dan entalpi mata air panas serta air meteorik. Berdasarkan analisis geoindikator $\mathrm{Cl}-\mathrm{Li}-\mathrm{B}$, diinterpretasikan terdapat dua sistem panas bumi dengan reservoir yang berbeda pada daerah penelitian yaitu Reservoir Cipanas dan Cilakar. Berdasarkan plot Na-K-Mg untuk mengetahui kesetimbangan fluida, MAP Cipanas merupakan fluida partial equilibrium sedangkan MAP Cilakar adalah fluida immature water. Temperatur reservoir panas bumi berdasarkan metode geotermometer $\mathrm{Na}-\mathrm{K}$ adalah $80^{\circ} \mathrm{C}$ untuk MAP Cipanas dan $60^{\circ} \mathrm{C}$ untuk MAP Cilakar. Sedangkan berdasarkan metode silika entalpi adalah $145^{\circ} \mathrm{C}$ untuk MAP Cipanas dan $164^{\circ} \mathrm{C}$ untuk MAP Cilakar.
\end{abstract}

Kata Kunci: bantarkawung; diagram silika vs entalpi; geotermometer Na-K; manifestasi panas bumi; temperatur reservoir

Abstract. Geothermal manifestations that appear in the Bantarkawung area and its surroundings as a reflection of the geothermal system are in the form of hot springs. Some hot springs that appear are Cipanas Hot Springs and Cilakar Hot Springs. The presence of hot springs is also followed by the presence of cold springs, some of which are Meteoric Warudoyong Springs and Meteoric Cilimus Springs as research supporting data. The analysis used in this research is geochemical method which is processed based on previous research data to determine the type of geothermal water, geo-indicator and fluid equilibrium. Determination of geothermal temperature in the study area using two methods, the geothermometer $\mathrm{Na}-\mathrm{K}$ method based on the content of sodium and potassium hot springs and the silicaenthalpy diagram method based on the content of silica and enthalpy of hot springs and meteoric water. Based on the geo-indicator analysis of $C-L i-B$, interpreted there are two geothermal systems with different reservoirs in the study area namely Cipanas and Cilakar Reservoir. Based on the $\mathrm{Na-K}-\mathrm{Mg}$ plot to determine fluid equilibrium, Cipanas MAP is a partial equilibrium fluid while Cilakar MAP is an immature water fluid. Geothermal reservoir temperature based on geothermometer Na-K method is $80^{\circ} \mathrm{C}$ for Cipanas MAP and $60^{\circ} \mathrm{C}$ for Cilakar MAP. While based on the method of silica enthalpy is $145^{\circ} \mathrm{C}$ for Cipanas MAP and $164^{\circ} \mathrm{C}$ for Cilakar MAP.

Keywords: bantarkawung; silica diagram vs enthalpy; geothermometer Na-K; geothermal manifestations; reservoir temperature

\section{PENDAHULUAN}

Manifestasi panas bumi mbentuk sebuah sistem panas bumi yang tersusun atas sumber panas, batuan reservoir, batuan penutup dan fluida panas bumi. Reservoir panas bumi adalah salah satu aspek penting tempat fluida yang terpanaskan oleh sebuah sumber panas. Fluida ini kemudian naik ke permukaan melalui rekahan batuan yang ada (Hadi,
2008). Pada umumnya, perhitungan temperatur reservoir panas bumi adalah menggunakan metode geotermometer. Penelitian ini menggunakan metode geotermometer dan metode entalpi-silika untuk mengetahui temperatur reservoir panas bumi. Penggunaan metode entalpi-silika (Fournier, 1977) adalah sebagai pembanding dengan metode yang biasa digunakan yaitu metode 
geotermometer. Data yang digunakan dalam analisis penelitian ini bersumber dari penelitian Harijoko dan Juhri tahun 2017. Penelitian ini ditekankan pada perhitungan temperature reservoir panas bumi dengan metode entalpi-silika yang belum dilakukan sebelumnya untuk dibandingkan dengan metode geotermometer.

Dari penelitian ini diharapkan diketahui nilai temperatur reservoir panas bumi dengan menggunakan metode entalpi-silika sebagai pembanding nilai temperatur reservoir dengan mnggunakan metode geotermometer. Penelitian dilakukan pada daerah panas bumi Bantarkawung, Brebes, Jawa Tengah. Manifestasi panas bumi pada daerah ini muncul sebagai mata air panas. Penelitian hanya dilakukan pada beberapa mata air dimana terdapat mata air panas dan dingin yang saling berdekatan dan jarak antar mata air yang sejenis berjauhan untuk mendapatkan hasil temperature reservoir berbeda. Kedua mata air panas yaitu Mata Air Panas Cipanas dan Mata Air Panas Cilakar. Selain menggunakan mata air panas, penelitian ini juga memanfaatkan keberadaan dua mata air meteorik pada daerah penelitian yaitu Mata Air Dingin Warudoyong dan Mata Air Dingin Cilimus (Gambar 1).

\section{Geologi Regional}

Daerah penelitian tersusun atas beberapa satuan batuan sedimen dan batuan beku dari beberapa umur menjadi susunan stratigrafi (Kastowo, 1996). Satuan batuan tertua di daerah

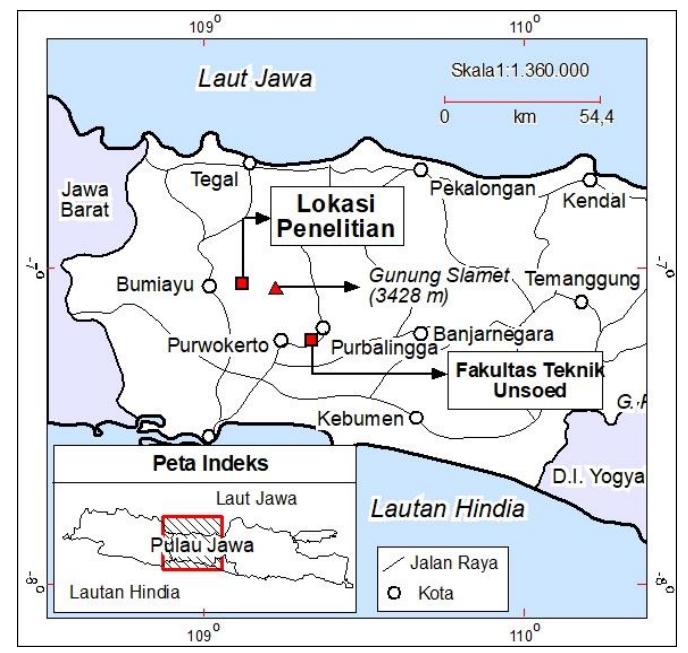

Gambar 1 Peta lokasi penelitian penelitian merupakan Formasi Rambatan yang tersusun atas batupasir gampingan dan konglomerat yang bersisipan dengan napal dan serpih pada bagian bawah. Di atas Formasi Rambatan, terendapkan secara menjari Formasi Halang dan Formasi Kumbang.

Formasi Halang tersusun atas batupasir tufan, konglomerat, napal dan batulempung serta breksi bersusun andesit di bagian bawah. Formasi Kumbang tersusun atas breksi gunungapi, lava, dan tuf bersusun andesit sampai basal, batupasir tuf dan konglomerat serta sisipan magnetit. Diatas dua formasi yang seumur ini terendapkan Formasi Kaliglagah yang terdiri dari batupasir kasar, konglomerat yang mengandung fosil moluska air tawar dan mamalia serta lempung dan napal. Selanjutnya diatas formasi ini terdapat Batuan Beku Tak Terurai yang tersusun atas andesit sampai basal berupa lava dan breksi aliran.

Di atas Formasi Kaliglagah dan batuan beku mengendap Formasi Mengger yang terdiri dari tuf kelabu muda, batupasir tufan, konglomerat dan pasir magnetit. Selanjutnya ada Formasi Gintung dengan komposisi batuan perselingan konglomerat bersusun andesit dengan batupasir kelabu hijau dan batulempung. Selanjutnya merupakan endapan muda yaitu Endapan Lahar Slamet yang terdiri atas lapisan lava. Satuan termuda pada daerah penelitian adalah alluvium yang terdiri dari kerikil, pasir dan lempung yang berwarna kelabu. Terdapat beberapa struktur geologi berupa sesar naik, sesar turun dan perlipatan yang dominan berarah barat laut-tenggara. Di sekitar Daerah Bantarkawung terdapat kemunculan mata air panas yang mengindikasikan kondisi immature water dan muncul pada zona outflow dari suatu sistem panas bumi (Iswahyudi dkk., 2013). Geologi daerah penelitian secara jelas terlihat pada Gambar 2.

\section{METODOLOGI}

Metode yang digunakan untuk menentukan temperatur reservoir panas bumi pada Daerah Bantarkawung adalah metode geokimia. Metode ini menggunakan data kimia berupa kandungan ion pada mata air panas dan air meteorik di daerah 
penelitian. Data kimia mata air panas dan air meteorik yang digunakan pada penelitian ini bersumber dari data penelitian Harijoko dan Juhri pada tahun 2017. Data kimia masing-masing mata air panas digunakan untuk analisis awal sebagai bahan pertimbangan saat menentukan temperatur reservoir panas bumi. Analisis awal yang dilakukan adalah analisis tipe air dengan diagram trilinear $\mathrm{Cl}$ $\mathrm{SO}_{4}-\mathrm{HCO}_{3} \quad$ (Nicholson, 1993), analisis geotermometer dengan diagram trilinear $\mathrm{Na}-\mathrm{K}-\mathrm{Mg}$ (Giggenbach, 1988) dan analisis geoindikator dengan diagram trilinear $\mathrm{Cl}-\mathrm{Li}-\mathrm{B}$. Analisis lanjut yang dilakukan adalah penentuan temperatur reservoir panas bumi menggunakan metode geotermometer dan diagram entalpi vs silika (Fournier, 1977).

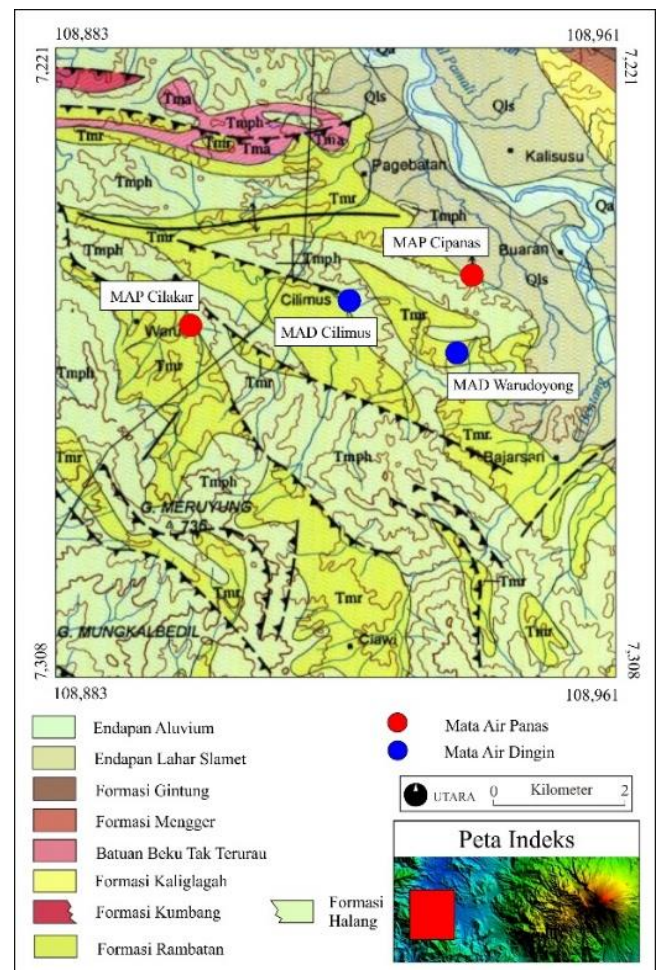

Gambar 2 Peta geologi daerah penelitian (Kastowo dan Suwarna, 1996 dengan modifikasi).

\section{HASIL DAN PEMBAHASAN}

Manifestasi panas bumi pada daerah Bantarkawung muncul sebagai mata air panas pada beberapa titik di daerah penelitian. Terdapat sekitar 5 titik pemunculan mata air panas di daerah Bantarkawung. Pada penelitian ini hanya digunakan 2 mata air panas yaitu Mata Air Panas Cipanas dan
Mata Air Panas Cilakar. Selain itu, penelitian ini juga memanfaatkan keberadaan Mata Air Meteorik Cilimus dan Mata Air Meteorik Warudoyong untuk menentukan temperatur reservoir panas bumi daerah Bantarkawung. Dari mata air panas dan air meteorik diambil data berupa major element dan temperatur tiap mata air, dalam hal ini digunakan data dari peneliti terdahulu seperti yang ditunjukkan pada Tabel 1.

Tabel 1. Data kandungan kimia ion mata air panas daerah penelitian

\begin{tabular}{ccccc}
\hline Mata Air & $\mathbf{1}$ & $\mathbf{2}$ & $\mathbf{3}$ & $\mathbf{4}$ \\
\hline $\mathrm{Temp}\left({ }^{\circ} \mathrm{C}\right)$ & 43 & 43,1 & 26,9 & 27,4 \\
$\mathrm{Na}(\mathrm{mg} / \mathrm{L})$ & 50,9 & 94,9 & 14 & 0,69 \\
$\mathrm{~K}(\mathrm{mg} / \mathrm{L})$ & 0,32 & 0,59 & 7,96 & 0,69 \\
$\mathrm{Mg}(\mathrm{mg} / \mathrm{L})$ & 0,04 & 18,6 & 15,8 & 5,31 \\
$\mathrm{Li} \mathrm{(mg/L)}$ & 0,01 & 0,01 & 0 & 0 \\
$\mathrm{~B}(\mathrm{mg} / \mathrm{L})$ & 3,37 & 1,64 & 0,3 & 0,35 \\
$\mathrm{Cl}(\mathrm{mg} / \mathrm{L})$ & 43,7 & 120 & 25,26 & 3,96 \\
$\mathrm{SO}_{4}(\mathrm{mg} / \mathrm{L})$ & 3,59 & 1,2 & 25,32 & 11,23 \\
$\mathrm{HCO}_{3}(\mathrm{mg} / \mathrm{L})$ & 54,9 & 132,17 & 195,4 & 201,3 \\
$\mathrm{SiO}_{2}(\mathrm{mg} / \mathrm{L})$ & 38,29 & 44,15 & 35,32 & 24,69 \\
\hline
\end{tabular}

\section{Keterangan}

$1=$ MAP Cipanas (Harijoko dan Juhri, 2017)

2 = MAP Cilakar (Harijoko dan Juhri, 2017)

$3=$ MAD Warudoyong (Harijoko dan Juhri, 2017)

$4=$ MAD Cilimus (Harijoko dan Juhri, 2017)

Sebelum menentukan temperatur reservoir panas bumi di daerah penelitian, hal yang pertama dilakukan adalah mengetahui tipe air dari masingmasing mata air panas. Data kimia yang digunakan dalam penentuan tipe air adalah klorida $(\mathrm{Cl})$, sulfat $\left(\mathrm{SO}_{4}\right)$ dan bikarbonat $\left(\mathrm{HCO}_{3}\right)$. Tiga ion tersebut diplot dalam segitiga untuk mengetahui posisi masing-masing mata air. Dari plot tersebut diketahui bahwa tipe air MAP Cipanas, MAP Cilakar, MAD Warudoyong dan MAD Cilimus adalah dilute chloride (bikarbonat/ $\mathrm{HCO}_{3}$ ). Tipe air ini adalah hasil pengenceran air klorida oleh air meteorik atau air bikarbonat saat mengalir menuju permukaan. Diagram trilinear penentuan tipe air ditunjukkan pada Gambar 3.

Hal yang penting dalam menentukan temperatur reservoir panas bumi adalah mengetahui tergolong dalam air manakah mata air 
panas daerah penelitian, apakah immature water, partial equilibrium atau full equilibrium.

Hal ketiga yang perlu diperhatikan dalam menentukan temperatur reservoir panas bumi adalah dengan mengetahui jumlah sistem panas bumi yang bekerja di daerah penelitian sehingga diketahui pula jumlah reservoirnya.

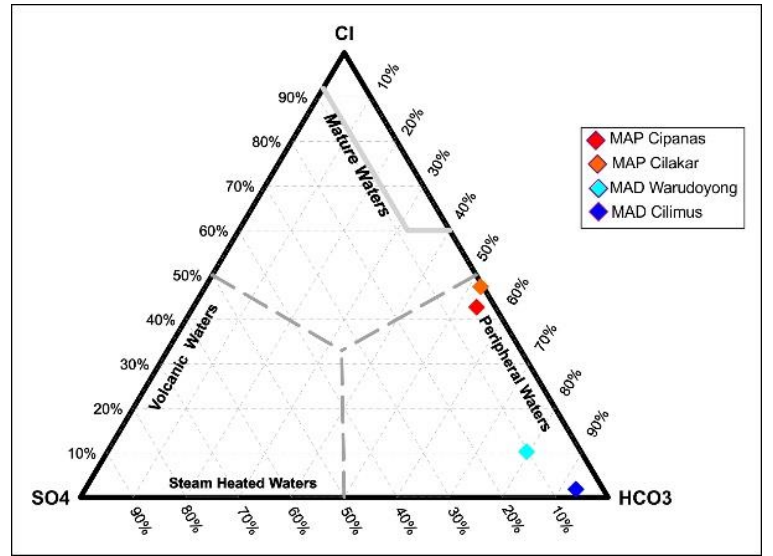

Gambar 3 Tipe mata air panas daerah penelitian.

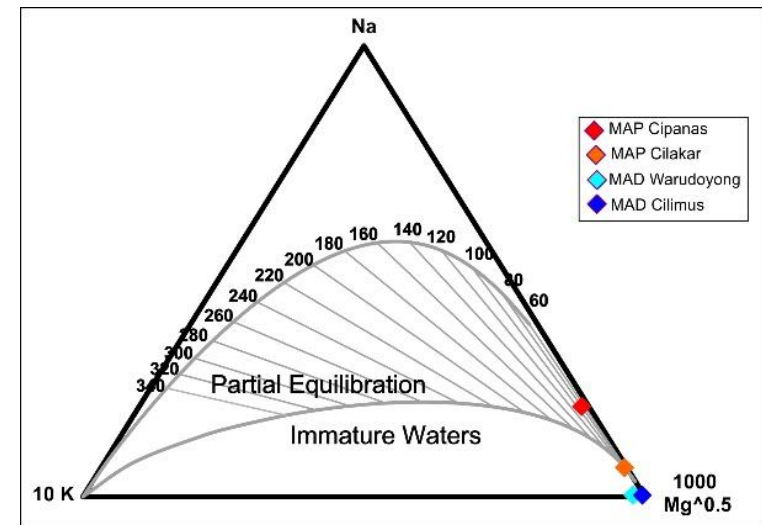

Gambar 4 Geotermometer mata air panas daerah penelitian

Apabila terdapat lebih dari satu resevoir maka penentuan temperatur reservoir dilakukan lebih dari sekali. Penentuan jumlah sistem panas bumi dilakukan dalam diagram trilinear geoindikator dengan melakukan plot ion klorida (Cl), litium (Li) dan boron (B). Setelah dilakukan plot dapat dilihat posisi masing-masing mata air panas, apabila posisi kelima mata air panas masih dalam satu kelompok dapat dikatakan berada dalam sistem panas bumi yang sama. Namun dari hasil plot diketahui terdapat kedua mata air panas daerah penelitian tidak berada dalam satu kelompok (terdapat dua sistem panas bumi) yaitu Cipanas dan Cilakar Penentuan ini dapat dilihat pada Gambar 5.

Setelah dilakukan analisis tipe air, geotermometer dan geoindikator, temperatur reservoir panas bumi dapat diketahui berdasarkan hasil ketiga analisis. Berdasarkan analisis geoindikator terdapat dua reservoir panas bumi berbeda pada daerah penelitian, sehingga akan

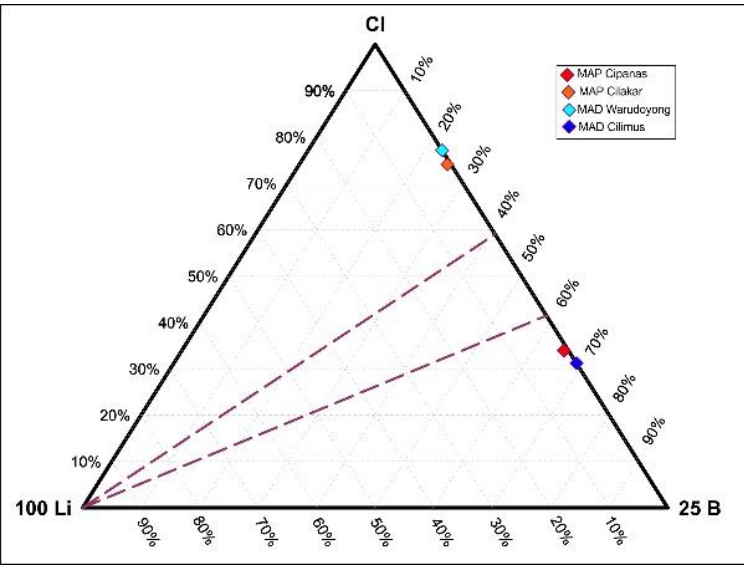

Gambar 5 Geoindikator mata air panas daerah penelitian.

terdapat dua perkiraan temperatur reservoir panas bumi. Berdasarkan analisis geotermometer Na-K, MAP Cipanas menunjukkan temperatur reservoir panas bumi sebesar $80^{\circ} \mathrm{C}$, sedangkan MAP Cilakar menunjukkan temperatur reservoir panas bumi sebesar $60^{\circ} \mathrm{C}$. Metode yang selanjutnya digunakan adalah dengan menggunakan diagram entalpi vs silika. Diagram ini menggunakan nilai entalpi dan jumlah ion silika mata air panas dan air meteorik untuk menentukan temperatur reservoir panas bumi. Terdapat dua asumsi yang dapat digunakan pada diagram entalpi silika. Asumsi maximum steam loss apabila panas hilang dari fluida reservoir sebelum fluida mencapai permukaan dan no steam loss apabila tidak ada panas yang hilang pada fluida reservoir. Mata air panas daerah penelitian menunjukkan temperatur yang cukup rendah sehingga digunakan sebagai indikasi untuk asumsi maximum steam loss. Penggunaan diagram entalpi silika dimulai dengan plot data entalpi dan kandungan ion silika mata air panas dan air meteorik ke dalam diagram. Data entalpi dan silika yang dimasukkan harus berdasarkan data yang 
diambil pada waktu sama dan terletak pada sistem panas bumi yang sama untuk tiap mata air panasnya. Untuk reservoir Cipanas, setelah data MAP Cipanas dan MAD Cilimus diplot dalam diagram, dibuat sebuah garis regresi dari titik mata mata air panas dan air meteorik sampai garis vertikal penanda boiling (419 kJ/k) maka akan didapatkan titik B. Dari titik tersebut dibuat sebuah garis vertikal ke kanan sampai berpotongan kurva maximum steam loss sebagai titik PT. Dari titik PT dibuat garis vertikal menuju sumbu entalpi sehingga didapatkan nilai entalpi untuk MAP Cipanas adalah

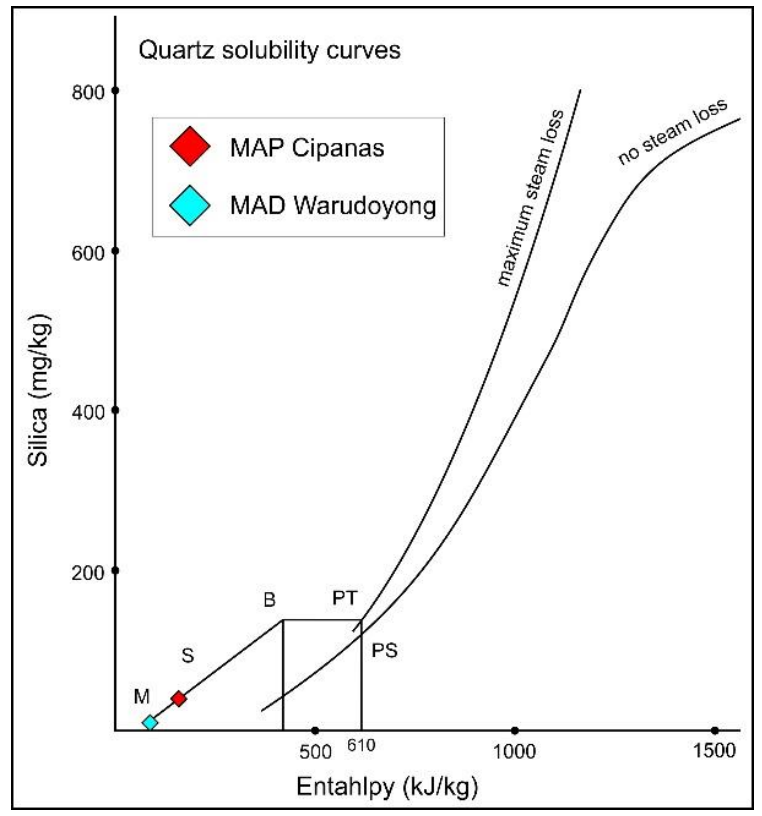

Gambar 1 Diagram entalpi vs silika Reservoir Cipanas

$610 \mathrm{~kJ} / \mathrm{kg}$. Dari nilai entalpi tersebut dan data steam table (Nicholson, 1993) diketahui bahwa temperatur reservoir Cipanas adalah $145^{\circ} \mathrm{C}$ (Gambar 6).

Hal yang sama juga berlaku untuk Reservoir Cilakar. Untuk Reservoir Cilakar didapatkan nilai entalpi yaitu sebesar $694,3 \mathrm{~kJ} / \mathrm{kg}$ untuk MAP Cilakar. Dari nilai entalpi tersebut dan data steam table (Nicholson, 1993) dapat diketahui temperatur Reservoir Cilakar yaitu $164^{\circ} \mathrm{C}$. Grafik penentuan temperatur untuk Reservoir Cilakar dapat dilihat pada Gambar 7.

Setelah dilakukan perhitungan temperatur reservoir daerah penelitian dengan metode $\mathrm{Na}-\mathrm{K}$ dan silika-entalpi, dapat dilihat perbedaan hasil dari kedua metode tersebut pada Tabel 2.

Tabel 2. Perhitungan temperatur reservoir metode geotermometer $\mathrm{Na}$-K dan entalpi-silika

\begin{tabular}{cccc}
\hline No. & Manifestasi & $\begin{array}{c}\text { Geotermometer } \\
\text { Na-K }\end{array}$ & $\begin{array}{c}\text { Entalpi- } \\
\text { Silika }\end{array}$ \\
\hline 1 & Cipanas & $80^{\circ} \mathrm{C}$ & $145^{\circ} \mathrm{C}$ \\
2 & Cilakar & $60^{\circ} \mathrm{C}$ & $164^{\circ} \mathrm{C}$ \\
\hline
\end{tabular}

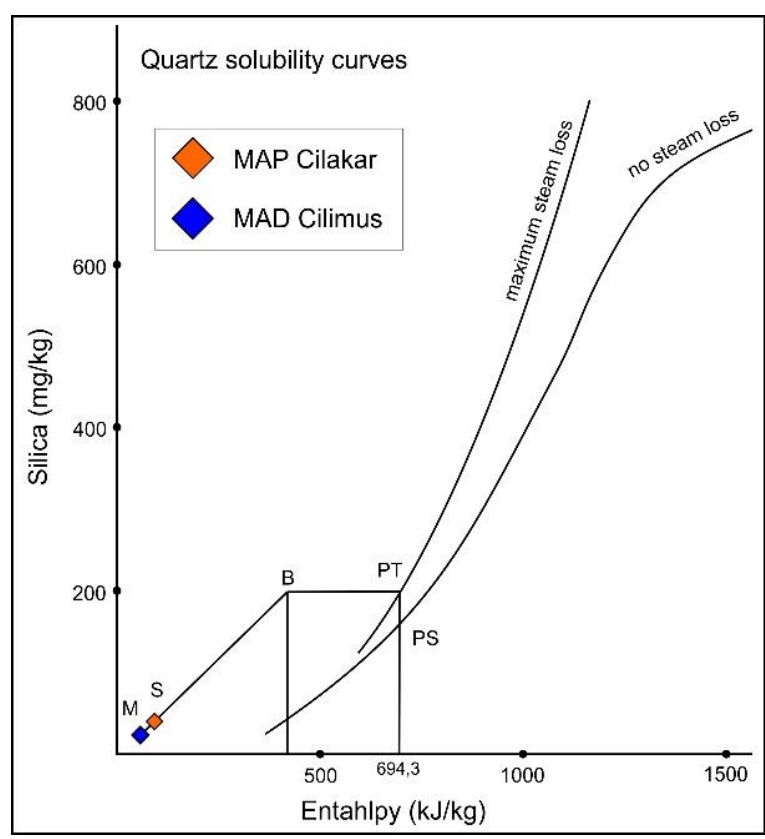

Gambar 2 Diagram entalpi vs silika Reservoir Cilakar

\section{PENUTUP}

\section{Kesimpulan}

Mata Air Panas Cipanas merupakan fluida yang termasuk dalam partial equilibrium yang sebagian telah mengalami perubahan sehingga tidak sepenuhnya setimbang, sedangkan Mata Air Panas Cilakar termasuk fluida yang berjenis immature water yang telah banyak mengalami proses sehingga tidak dalam keadaan setimbang. Berdasarkan diagram trilinear geoindikator, terdapat dua sistem panas bumi yang bekerja pada daerah penelitian yaitu Sistem Panas Bumi Cipanas dan Sistem Panas Bumi Cilakar. Dari keberadaan kedua sistem panas bumi tersebut dapat diketahui temperatur reservoir panas bumi daerah penelitian. Berdasarkan metode geotermometer $\mathrm{Na}-\mathrm{K}$ adalah $80^{\circ} \mathrm{C}$ umtuk Reservoir Cipanas dan $60^{\circ} \mathrm{C}$ untuk 
Reservoir Cilakar, sedangkan berdasarkan metode diagram entalpi-silika adalah sebesar $145^{\circ} \mathrm{C}$ untuk Reservoir Cipanas dan $164^{\circ} \mathrm{C}$ untuk Reservoir Cilakar.

\section{Ucapan Terima Kasih}

Ucapan terimakasih kami sampaikan kepada Lembaga Penelitian dan Pengabdian Masyarakat Unsoed, staf pengajar Teknik Geologi Unsoed dan pihak-pihak yang membantu dalam penyelesaian tulisan ini.

\section{DAFTAR PUSTAKA}

Fournier, R.O. (1977), "Chemical Geothermometers and Mixing Models for Geothermal Systems", Geothermics, Vol.5, No.1-4, hal. 41-50. http://doi.org/10.1016/0375-6505(77)90007-4.

Giggenbach, W.F. (1988), "Geothermal solute equilibria. Derivation of Na-K-Mg-Ca geoindicators", Geochimica et Cosmochimica Acta, Vol.52, No.12, hal. 27492765 . http://doi.org/10.1016/0016-7037(88)901433.

Hadi, A.U. (2008), "POTENSI DAN WILAYAH KERJA PERTAMBANGAN PANAS BUMI DI INDONESIA", MTG, Vol.1, No.2. Diambil dari http://jurnal.upnyk.ac.id/index.php/mtg/article/view $/ 177$.

Harijoko, A. dan Juhri, S. (2017), "Cl/B Ratio of Geothermal Fluid around Slamet Volcano, Jawa Tengah, Indonesia", IOP Conference Series: Earth and Environmental Science, Vol.103, hal. 012015. http://doi.org/10.1088/1755-1315/103/1/012015.

Iswahyudi, S., Widagdo, A., Subana dan Herdianita, R. (2013), Iswahyudi, S., Widagdo, A., Subana, and Herdianita, N.R. (2013): "Outflow Zone Indication of Geothermal System in Paguyangan Hotspring, Brebes, Central Java", Proceedings, 2nd ITB Geothermal Workshop 2013, Institut Teknologi Bandung.,.

Kastowo (1996), Peta geologi lembar Majenang, Jawa: Geological map of the Majenang quadrangle, Jawa, Peta geologi bersistem Indonesia = Systematic geological map of Indonesia ; Pusat Penelitian dan Pengembangan Geologi.

Nicholson, K. (1993), Geothermal Fluids: Chemistry and Exploration Techniques, Springer-Verlag, Berlin Heidelberg. Diambil dari https://www.springer.com/de/book/9783642778469 . 